\title{
Research on the Planning and Design of Modern Agricultural Industrial Park in China as well as its Actuality
}

\author{
Lao Xiu xia \\ Guangdong AIB Polytechnic College Guangzhou, Guangdong province 510507
}

\begin{abstract}
Developing modern agricultural industry park is one of the important ways of reforming modern agricultural in China. Based on understanding the research status of modern agricultural parks at home and abroad, this paper analyses the current situation and existing problems of the construction of modern agricultural parks in China, and puts forward five emphases of park planning and design: leisure tourism, sustainable development, agricultural informatization, circular economy and green industry.
\end{abstract}

Keywords: modern agricultural industry park; planning and design

\section{Introduction}

Modern agricultural industrial park refers to give priority to the development of modern agriculture within certain advantages in resources, industry and location, so as to form a cluster of industrial groups in a certain space. It is guided by the government and enterprises that implements intensive production and enterprise management on the basis of large-scale farming so as to build a comprehensive park with a wide range of functions, ranging from agricultural production, science and technology research, ecological protection, leisure tourism, model service, innovation incubation and so on. It aims to further promote the development of modern agriculture by increasing the farmers' income, driving the development of regional economy and industry.

Chinese agriculture is under reform of its upgrade in driving forces, change in development mode and the optimization of structure. Under such complex background, developing modern agriculture industrial parks is one of the important ways to implement reform which plays a positive role in cultivating kinetic energy in rural economy and increasing employment opportunities and farmers' incomes in rural areas so as to gradually accelerate the development of modern agriculture. In recent years, China has paid more and more attention to the development of modern agricultural industrial parks and its standardization and has made specific instructions in relevant documents. The 2016 central rural work conference clearly pointed out that modern agricultural industrial parks are important carriers for the optimization of agricultural industrial structure and the deep integration of "the Three Main Industries". In 2017, the No.1 document of the central government first proposed the idea of building a modern agricultural industrial park of "production + processing + science and technology" to promote its rapid development. In May 2018, the Ministry of Agriculture and Rural Affairs and the Ministry of Finance jointly issued the notice on the Establishment of national modern agricultural industrial park in 2018, 
regulating the conditions and tasks for the establishment of China's national modern agricultural industrial parks.

\subsection{Overseas and Domestic Research Status}

\subsubsection{Research on foreign modern agricultural industrial parks}

Since the 1990s, with the development of technological progress, economic globalization and the rise of new production system, high-tech parks and technical parks has emerged(Benko G 2000) [1]. Some countries implement some policies to promote the formation of knowledge clusters through resource aggregation, and encourage the establishment of cooperation among enterprises, research institutions and universities so as to stimulate the construction of technology parks and science parks. In the past decades, countries around the world have set up knowledge clusters such as technology parks, science parks and industrial parks, which play an important role in technological innovation, transformation and application of research results, and dissemination of knowledge and technology. Foreign agricultural parks mainly show new production modes to farmers and tourists by presenting advanced agricultural facilities and high-techs (Goldstein H A, 1987) [2]. There are three models: demonstration farm, leisure farm or sightseeing farm and education farm. At the same time, foreign scholars have done a lot of research on modern agricultural parks, including the relevant theoretical basis of modern agricultural parks, the evaluation system of the parks, etc.

In terms of basic theories, he mainly put forward the theory of agricultural location (Johann Heinrich von Thünen, 1826), the theory of technological innovation (Schumpeter, 1926), the theory of development (F.Perroux, 1950), the theory of technological induction (Fenonratan, 1985), and the theory of compound ecological agriculture (rodstie, 1986). As for the research on evaluation system, the earliest scholars involved in the field of park evaluation were American scholars Frater M. Rogers and Judith k. Larson. They systematically investigate the growth and start-up process of "silicon valley" through quantitative analysis and revealed the condition about the formation of "cohesive economic effect" in silicon valley. Since then, studies on the park evaluation index system in the United States have focused on the two fields related to the conditions and factors for the success of the parks (Maskey R K, 1997) [3].

\subsubsection{Research on domestic modern agricultural industrial park}

As for the research of modern agricultural industrial parks, domestic scholars mainly focus on the modern agricultural industrial parks in a certain region and provide reference for the development of national modern agricultural industrial parks through detailed analysis. The research angles mainly concentrate on the planning and construction, types and characteristics, functional positioning, operation mode, management system and performance evaluation of modern agricultural parks.

(1)Research on planning and construction. Domestic scholars have done a lot of researches on the planning of modern agricultural industrial parks, most of which take a certain region as a case study, and try to use different scientific planning methods to provide reliable suggestions for the planning and design of modern agricultural industrial parks. Liu Shan and Liu Zheng (2011) made an overall plan from the perspectives of agricultural 
development concept and ideas, target positioning, industrial structure design, and industrial functional zone. They believed that the planning and construction of modern agricultural industrial parks should be combined with the principles of science and technology as the guide, industry as the orientation, principle of overall development and multiple input. According to the development requirements of the industrial parks, the planning and design are carried out to reasonably match the area planning of each part. It highlights high technology content, first-class varieties and science and technology, and adopts arrangement that focus on integration of industry, education and research, of production and promotion and of manufacturing and marketing ${ }^{[4]}$. Xu Bifang and Xiao Guangjiang (2013) elaborated in detail that planning and design play an important role in clarifying the position of modern industrial park, highlighting the characteristics of the park, and improving the function and scientific and reasonable layout of the park. They also proposed key technologies and effective measures for the existing problems from the aspect of planning and design innovation, aiming to ensure the scientific, sustainable and innovative construction of modern agricultural industrial park, so as to offer some helpful reference for the development of modern agriculture ${ }^{[5]}$. Taking modern agricultural industrial park in Qilin district as an example, Li Jianguang and Shen Yuxian (2018) proposed that rational planning and layout should be carried out in the planning and design of new agricultural industrial parks. While creating the park landscape with distinctive aesthetic value, the most prominent local characteristics of agricultural tourism should be maintained to provide tourists with a tranquil and elegant tourism environment different from the city ${ }^{[6]}$.

(2)Other kinds of researches. Liu Yanjiao et al. (2015) elaborated the basic characteristics, main functions and types of modern agricultural industrial parks in China in detail on the basis of a large number of investigations, and made a detailed review of relevant research status, pointing out the future development trend of modern agricultural industrial parks in China ${ }^{[7]}$. Luo Le et al. (2010) took Shanghai modern agricultural industrial park as an example to analyze the problems existing in its operation mode, such as backward information, insufficient innovation, lack of cultural atmosphere, and unclear functions and regional characteristics. They proposed to develop agricultural high-tech industries in line with city and district conditions, set up reasonable land transfer mechanism, promote largescale land management, and establish perfect modern enterprise management system based on mechanism innovation ${ }^{[8]}$.Jiang Jing(2013) extracted and summarized six development modes of national modern agriculture demonstration zones: mode driven by industrial parks in developed areas in the east, by grain production in major grain producing areas in plains, by active grain base in hilly and mountainous areas, by urban-rural coordination in small and medium-sized cities, by modern agriculture in urban suburbs of large cities, and by large-scale farms in reclamation areas. And the reference functions of the six models to other agricultural industrial parks are also under discussion ${ }^{[9]}$.

In conclusion, foreign scholars' researches on modern agricultural industrial parks are more mature, while domestic researches tend to be fragmented and lack of systematic research. This paper mainly analyzes the current situation and problems of modern agricultural industrial parks in China on the basis of previous studies, and conducts research and discussion on the planning and design of modern agricultural industrial parks. 


\subsection{Development status and problems of modern agricultural industrial park in China}

\subsubsection{Development status}

Modern agricultural industrial park in China has gone through three stages: exploration (1993-2003), development (2004-2009) and take-off (2009-present). At present, there are three batches of 153 national modern agricultural industrial parks in China, distributing throughout the country.

At present, 153 modern agricultural industrial parks in China can be classified into 5 categories according to their competitive industries :(1) grain-producing agricultural industrial parks represented by Sichuan, Henan and Hebei provinces. This type of agricultural industrial park occupies large cultivated area, leveling land and fertile soil, with emphasis on high-yield planting of grain cotton oil, comprehensive agricultural development and promotion of mechanized production. (2)efficient agricultural industrial parks represented by Hainan, Guangdong and Fujian provinces. This region is located in the coastal area, with developed economy and trade, land shortage, dry climate and lack of fresh water resources, and focuses on the development of high value-added aquatic products, fruits, flowers, vegetables and other export products. (3)economical agricultural industrial parks represented by Qinghai, Gansu and Ningxia provinces. This areas focus on the development of water-saving, fertilizer-saving, land-saving agriculture. (4) regional characteristic agricultural industrial parks represented by Chongqing, Yunnan and Guizhou provinces.These areas are hills and plateau, with diverse ecology and climate, focusing on the development of characteristic agricultural products, such as highland vegetables, flowers and tea. (5) urban agriculture demonstration area represented by Beijing and Shanghai. This region has always been an economic center with superior geographical location and developed science and technology. However, there is less land available for agriculture, and the focus is to develop characteristic agriculture with small area and high efficiency, as well as high-tech agriculture, leisure agriculture and exhibition agriculture.

\subsubsection{Existing Problems}

(1)Planning layout is unbalanced. Modern agricultural industrial parks attach such great importance in its preliminary planning, positioning and core development goals that its development layout and regional scope should be identified. At present, the unreasonable distribution of agricultural industrial parks fails to match up with local township construction and land planning; the construction of parks remains to be improved, together with the ability of coordinated development between local competitive industries and regional characteristic industries; the construction of parks is sprawling blindly. All these problems has ruined the development vitality that sustains the construction of the industrial parks. (2)The effect of green development is not so satisfying. Through integration of farming and breeding as well as agricultural cleaner production, modern agricultural industrial parks have been exploring a quality-assured pathway for green development with highly efficient production. However, agricultural environmental pollution still exists in some agricultural industrial parks. So there is still a long way for them to go in controlling the total amount of agricultural water consumption, reducing the usage of chemical fertilizer and pesticides and utilizing agricultural waste. Besides, green, low-carbon and recycled development mechanism hasn't well established in some parks, which impedes the quality and branding of agricultural development. 


\subsection{Planning and design for modern agricultural industrial parks}

It is necessary to plan and design the modern agricultural industrial parks based on their natural conditions, financial situation, development status and infrastructures. A scientific, rational and systematic design scheme should be mapped out to divide the parks into different functional areas according to the varieties and industries, such as vegetable industry functional area, fruit functional area, agricultural tourism zone, central control district, etc., so as to facilitate the parks with distinctive features and high efficiency. The planning and design will lay emphasis on following five priorities:

(1) Leisure travel. Modern agricultural parks are not only demonstration areas in farm production, but also good destinations for travelling and relaxation. Therefore, the layout and design of the industrial parks, beginning from the perspective of tourism, find out tourists' demand and purposes to modern agricultural industrial parks and incorporate them into the planning.

(2) Sustainable development. Sustainable development means a comprehensive, balanced and healthy development in recycling, energy conservation and environmental protection. Introducing sustainable concept into modern agricultural production enables a green and environmental-friendly production model that can save energy, protect the ecology and decrease environmental costs. In addition, the sustainability and green ecological idea should also be integrated into the distribution and design of those industrial parks.

(3) Agricultural information. Modern agriculture, instead of being confined to the traditional modes, requires more science and technology (e.g. IT) for production. Information control can be applied to Managing the series of process of agricultural production and sales to make the work easier and avoid or lessen the effects or risks from various aspects. To some extent, information technology ensures a stable development of modern agriculture, raising the industry's economic benefit.

(4) Recycling economy. Another way for a rational, scientific planning design with sustainable development is adhering to recycling economy, a renewable and recirculated production pattern, which can alleviate environmental pollution and resource and energy waste. So it is the precondition for sustainable development to bringing recycling economy into the planning of modern agricultural industrial parks.

(5) Industrial green development. Improving living standards and quality has advanced higher demands for produce's quality, which is hoped to be green, healthy and additive-free. This has prompted the industrial parks to renew their own science and technology and grow green produce in the technology of recycling in order to prevent the agroecological environment from pollution and achieve holistic and balanced sustainability. Both the quantity and quality should be guaranteed before those pollution-free produce being put into the market.

\section{Conclusion}

The planning and programming of modern agricultural industrial parks plays an important role in its sustainable development and well reflects the requirements of modern agriculture in sustainability, environmental protection, recycling economy and leisure travelling, while realizing the scientific and reasonable layout of the parks. For all this, it is possible to greatly 
enhance the efficiency and quality of agricultural production and bring huge economic benefit of the parks.

\section{References}

[1] Benko G. Technopoles, high-tech industries and regional development: A critical review[J]. Geojournal, 2000, 51(3):157-167.

[2] Goldstein H A, Luger M I. Science/Technology Park in the United Sates and Regional Development Theories[M].1987:56

[3] Maskey RK. Sustainable agricultural development in less developed countries[J]. Outlook on Agriculture, 1997, 26(1):39-45.

[4] LIU Shan,LIU Zheng. Study on Plan and Design of Modern Agriculture Demonstration Garden[J].Journal of Anhui Agri. Sci.,2011,39(35):21875-21876.

[5] XU bi-fang,XIAO Guang-jiang. Applied study on importance and creation of the plan and design for development of modern agricultural park in China[J]. Guangdong Agricultural Sciences. ,2013,40(2):202-204.

[6] LI Jian-guang,SHEN Yu-xian. Study on Planning and Design of New Agricultural Parks: A Case Study of Qujing Qilin Modern Agricultural Demonstration Park [J]. Research on Urban Construction Theory (Electronic Edition),2018(5).

[7] LIU Yan-jiao. A Summary of the Basic Characteristics, Functions and Types of Modern Agricultural Parks in China [J]. Chinese Horticultural Abstracts,2015(2):45-47.

[8] LUO Le,LIU Hai-wei,CHEN Wei-kang. Study on the Problems and Countermeasures of the Operation Mode of Shanghai Modern Agricultural Park [J]. Hunan Agricultural Sciences,2010(15):148-150.

[9] JIANG Jing. Study on Operation Mechanism and Development Model of National Modern Agricultural Demonstration Zone [D]. Chinese Academy of Agricultural Sciences 2013. 